\title{
Association between the XKR6 rs7819412 SNP and serum lipid levels and the risk of coronary artery disease and ischemic stroke
}

\author{
Peng-Fei Zheng ${ }^{1}$, Rui-Xing Yin ${ }^{1,2,3^{*}}$ D, Guo-Xiong Deng ${ }^{1}$, Yao-Zong Guan ${ }^{1}$, Bi-Liu Wei ${ }^{1}$ and Chun-Xiao Liu ${ }^{1}$
}

\begin{abstract}
Background: The present study aimed to expound the association between the XK related 6 gene (XKR6) rs7819412 single nucleotide polymorphism (SNP) and serum lipid profiles and the risk of coronary artery disease (CAD) and ischemic stroke.

Methods: The genetic makeup of the XKR6 rs7819412 SNP in 1783 unrelated participants (controls, 643; CAD, 588 and ischemic stroke, 552) of Han Chinese was obtained by the Snapshot technology.

Results: The genotypic frequencies of the SNP were disparate between CAD (GG, 81.0\%; GA/AA, 19.0\%) or ischemic stroke (GG, 81.2\%; GA/AA, 18.8\%) patients and healthy controls (GG, 85.7\%, GA/AA, 14.3\%; $P<0.05$ vs. CAD or ischemic stroke; respectively). The A allele frequency was also diverse between CAD (10.1\%) or ischemic stroke (10.0\%) and control groups (7.5\%; $P<0.05$ vs. CAD or ischemic stroke; respectively). The GA/AA genotypes and A allele were associated with high risk of CAD and ischemic stroke (CAD: $P=0.026$ for GA/AA vs. GG, $P=0.024$ for $A$ vs. G; Ischemic stroke: $P=0.029$ for GA/AA vs. GG, $P=0.036$ for $A$ vs. G). The GAAA genotypes were also associated with increased serum triglyceride (TG) concentration in CAD and total cholesterol (TC) concentration in ischemic stroke patients.

Conclusions: These data revealed that the XKR6 rs7819412 A allele was related to increased serum TG levels in CAD, TC levels in ischemic stroke patients and high risk of CAD and ischemic stroke.
\end{abstract}

Keywords: Coronary artery disease, Ischemic stroke, XKR6, Single nucleotide polymorphism, rs7819412, Lipids

\section{Background}

Dyslipidemia is a heritable risk factor for coronary artery disease (CAD) which contributed to a prominent reason of disability, mortality, morbidity, functional deterioration and expensive healthcare, and accounts for approximately $30 \%$ of all the deaths worldwide [1-3]. Previous studies have shown that CAD occurs due to various factors and can be subjective to genomic background, lifestyle, environmental factors and alterations of plasma lipid levels as well as their interactions with each other $[4,5]$. Atherosclerosis is generally considered

\footnotetext{
* Correspondence: yinruixing@163.com

'Department of Cardiology, Institute of Cardiovascular Diseases, the First Affiliated Hospital, Guangxi Medical University, Nanning 530021, Guangxi, People's Republic of China

${ }^{2}$ Guangxi Key Laboratory Base of Precision Medicine in

Cardio-cerebrovascular Disease Control and Prevention, Nanning 530021,

Guangxi, People's Republic of China

Full list of author information is available at the end of the article
}

to be the pathological foundation of CAD [6] and ischemic stroke [7], which is caused by the accumulation of cholesterol in arterial wall macrophages and the dysregulation of metabolic rate of lipids for example increased levels of low-density lipoprotein cholesterol (LDL-C) [8], and apolipoprotein (Apo) B [9], triglyceride (TG) [10], total cholesterol (TC) [11], along with reduced levels of high-density lipoprotein cholesterol (HDL-C) [12] and ApoA1 [9] in serum. In addition, hereditary elements are deemed to account for about $50-80 \%$ of the incidence of dyslipidemia [13] and $30-60 \%$ of the occurrence of CAD and ischemic stroke [14].

Many genetic loci that are closely associated with lipid metabolism were identified by genome-wide association studies (GWASes), and specific loci among them were also found to be associated with CAD, type 2 diabetes (T2DM), hypertension, and body mass index (BMI) [15]. Previous GWAS has demonstrated that the rs7819412

(c) The Author(s). 2019 Open Access This article is distributed under the terms of the Creative Commons Attribution 4.0 International License (http://creativecommons.org/licenses/by/4.0/), which permits unrestricted use, distribution, and reproduction in any medium, provided you give appropriate credit to the original author(s) and the source, provide a link to the Creative Commons license, and indicate if changes were made. The Creative Commons Public Domain Dedication waiver (http://creativecommons.org/publicdomain/zero/1.0/) applies to the data made available in this article, unless otherwise stated. 
single nucleotide polymorphism (SNP) near the XKR6 gene (XKR6; also knows as: XRG6; C8orf5; C8orf7; C8orf21, GeneID: 286046, HGNC: 27806, locus type: gene with protein product, located in chromosome 8p23.1) was associated with TG levels and T2DM in Europeans [16]. Nevertheless, the association between the XKR6 rs7819412 SNP and blood lipid levels and the risk of CAD and ischemic stroke is not clear and not reported in the Han Chinese. Thus, this study was designed to understand the relationship between the XKR6 rs7819412 SNP and several serum lipid parameters and the risk of CAD and ischemic stroke in the Han Chinese.

\section{Methods}

\section{Subjects}

A total of 552 unrelated patients with ischemic stroke and 588 participants with CAD were selected from the First Affiliated Hospital of Guangxi Medical University. CAD was defined as significantly coronary artery stenosis ( $\geq 50 \%)$ in at least anyone of the three main coronary vessels or their main branches (branch diameter $\geq 2$ $\mathrm{mm}$ ) [17]. All of the patients with ischemic stroke have received a brain magnetic resonance imaging (MRI) scan and strict neurological examination. The diagnostic criteria for ischemic stroke were derived from the International Classification of Diseases (9th Revision). All subjects with a history of type 1 diabetes, neoplastic, autoimmune, liver, hematologic, thyroid, and renal were excluded. Patients with CAD had no history of ischemic stroke and patients with ischemic stroke also had no history of CAD.

A total of 643 healthy controls matched by ethnic group (Han Chinese), age, gender were also recruited. All subjects were healthy and none of them had a history of CAD, myocardial infarction (MI), ischemic stroke and T2DM as judged by history taking, questionnaires, and critical clinical examination. All participants were randomly collected from the Physical Examination Center of the First Affiliated Hospital, Guangxi Medical University in the same period. Before the beginning of the research, all participants had signed a written informed consent. The research proposal was approved by the Ethics Committee of the First Affiliated Hospital, Guangxi Medical University (No: Lunshen-2011-KYGuoji-001; Mar. 7, 2011).

\section{Genotyping and biochemical assays}

A venous blood sample of $5 \mathrm{ml}$ was collected from each participant after at least $12 \mathrm{~h}$ of fasting. Part of the sample $(2 \mathrm{ml})$ was placed in a glass tube and used to determine serum lipid levels. The remaining sample $(3 \mathrm{ml})$ was collected in the tubes containing anticoagulants $(4.80 \mathrm{~g} / \mathrm{L}$ citric acid, $14.70 \mathrm{~g} / \mathrm{L}$ glucose, $13.20 \mathrm{~g} / \mathrm{L}$ tri-sodium citrate) and was utilized to extract deoxyribonucleic acid (DNA).
Genotyping of the XKR6 rs7819412 SNP (rs7819412F: 5' CGAGTGGTTCTTCCCAGCATGT-3' and rs7819412R: 5'-ATGTGCCCCCACACCATCATT-3') was performed by the Snapshot technology [18]. Methods for the detection of serum HDL-C, LDL-C, ApoA1, TC, ApoB, TG levels were referred to our previous study [19]. Serum lipid levels were tested using an autoanalyzer (Type 7170A; Hitachi Ltd., Tokyo, Japan) in the Clinical Science Experiment Center of the First Affiliated Hospital, Guangxi Medical University [20, 21].

\section{Diagnostic criteria}

The levels of serum TG $(0.56-1.70 \mathrm{mmol} / \mathrm{L}), \mathrm{ApoB}$ $(0.80-1.05 \mathrm{~g} / \mathrm{L})$, TC $(3.10-5.17 \mathrm{mmol} / \mathrm{L})$, LDL-C $(2.70$ $3.10 \mathrm{mmol} / \mathrm{L})$, ApoA1 $(1.20-1.60 \mathrm{~g} / \mathrm{L})$, HDL-C (1.16$1.42 \mathrm{mmol} / \mathrm{L}$ ), and the ApoA1/ApoB ratio (1.00-2.50) were defined as normal values at our Clinical Science Experiment Center. The diagnostic criteria of hyperlipidemia, hypertension, obesity, normal weight, and overweight were referred to previous studies [19-24]. Somebody who has been previously diagnosed with diabetes or people with $2 \mathrm{~h}$ postprandial plasma glucose $\geq 11.1 \mathrm{mmol} / \mathrm{L}$ or a fasting plasma glucose $\geq 7.0 \mathrm{mmol} / \mathrm{L}$ were defined as diabetic patients [25].

\section{Statistical analyses}

All data were evaluated using SPSS (Version 22.0). Values were presented as mean \pm SD. Hardy-Weinberg equilibrium was verified by standard goodness of fit test. The chi-square test was used to calculate the genotype distribution between cases and controls. Independentsamples $t$ test was used to analyze the difference in general characteristics between patients and controls. The relationship between serum lipid levels and genotypes was tested by covariance analysis (ANCOVA). Gender, age, blood pressure, cigarette smoking, BMI and alcohol consumption were adjusted for the statistical analysis. Unconditional logistic regression analysis was used to detect the odds ratio (OR) and 95\% confidence interval (CI). The heart-map of the inter-locus models was measured by R software (version 3.5.3). A $P$-value $<0.05$ was considered as statistically significant.

\section{Results}

\section{Common and biochemical characteristics}

As mentioned in Table 1, the ratio of female to male, age, serum ApoB levels and the proportion of smokers were similar between the controls and cases. The height, weight, BMI, systolic blood pressure, glucose, pulse pressure, serum LDL-C, TG and TC levels were significantly lower; and serum HDL-C and ApoA1 levels, the ApoA1/ $A p o B$ ratio, and the proportion of drinkers were significantly higher in controls than in CAD and ischemic stroke patients. The level of diastolic blood pressure was 
Table 1 Comparison of demographic, lifestyle characteristics and serum lipid levels of the participants

\begin{tabular}{|c|c|c|c|c|c|}
\hline \multirow[t]{2}{*}{ Characteristic } & \multirow{2}{*}{$\begin{array}{l}\text { Control } \\
(n=643)\end{array}$} & \multicolumn{2}{|l|}{ Case } & \multicolumn{2}{|c|}{$P$ vs. controls } \\
\hline & & $\begin{array}{l}\text { CAD } \\
(n=588)\end{array}$ & $\begin{array}{l}\text { Ischemic stroke } \\
(n=552)\end{array}$ & $\overline{P_{C A D}}$ & $P$ Ischemic stroke \\
\hline Male/female & $473 / 170$ & $432 / 156$ & $400 / 152$ & 0.936 & 0.670 \\
\hline Age (years) & $61.61 \pm 11.95$ & $62.32 \pm 10.53$ & $62.73 \pm 12.37$ & 0.270 & 0.111 \\
\hline Height (cm) & $155.08 \pm 7.84$ & $164.11 \pm 6.97$ & $163.88 \pm 7.12$ & 0.000 & 0.000 \\
\hline Weight (kg) & $54.56 \pm 9.00$ & $64.50 \pm 10.68$ & $63.14 \pm 11.04$ & 0.000 & 0.000 \\
\hline BMI $\left(\mathrm{kg} / \mathrm{m}^{2}\right)$ & $22.66 \pm 3.19$ & $23.87 \pm 3.24$ & $23.44 \pm 3.45$ & 0.000 & 0.000 \\
\hline Smoking, $n \%$ & $250(38.8)$ & $248(42.2)$ & $230(41.7)$ & 0.239 & 0.327 \\
\hline Alcohol, $n$ \%) & $277(43.1)$ & 133 (22.6) & $156(28.3)$ & 0.000 & 0.000 \\
\hline $\mathrm{SBP}(\mathrm{mmHg})$ & $128.05 \pm 19.00$ & $132.93 \pm 23.40$ & $147.86 \pm 21.89$ & 0.000 & 0.000 \\
\hline $\mathrm{DBP}(\mathrm{mmHg})$ & $80.41 \pm 11.42$ & $79.25 \pm 14.15$ & $83.84 \pm 12.79$ & 0.111 & 0.000 \\
\hline $\mathrm{PP}(\mathrm{mmHg})$ & $47.64 \pm 13.97$ & $53.68 \pm 17.54$ & $64.02 \pm 17.75$ & 0.000 & 0.000 \\
\hline Glu (mmol/L) & $6.01 \pm 1.60$ & $6.25 \pm 1.48$ & $6.20 \pm 1.45$ & 0.008 & 0.037 \\
\hline TC (mmol/L) & $4.34 \pm 1.05$ & $4.55 \pm 1.22$ & $4.54 \pm 1.16$ & 0.001 & 0.002 \\
\hline TG (mmol/L) & $1.38 \pm 1.77$ & $1.65 \pm 1.11$ & $1.68 \pm 1.46$ & 0.001 & 0.002 \\
\hline $\mathrm{HDL}-\mathrm{C}(\mathrm{mmol} / \mathrm{L})$ & $1.90 \pm 0.49$ & $1.15 \pm 0.34$ & $1.23 \pm 0.41$ & 0.000 & 0.000 \\
\hline LDL-C (mmol/L) & $2.72 \pm 0.77$ & $2.86 \pm 1.02$ & $2.83 \pm 0.91$ & 0.009 & 0.029 \\
\hline ApoA1 (g/L) & $1.42 \pm 0.27$ & $1.03 \pm 0.35$ & $1.03 \pm 0.23$ & 0.000 & 0.000 \\
\hline ApoB (g/L) & $0.90 \pm 0.21$ & $0.91 \pm 0.27$ & $0.89 \pm 0.24$ & 0.588 & 0.507 \\
\hline ApoA1/ApoB & $1.65 \pm 0.56$ & $1.24 \pm 0.80$ & $1.25 \pm 0.50$ & 0.000 & 0.000 \\
\hline
\end{tabular}

SBP Systolic blood pressure, DBP Diastolic blood pressure, $P P$ Pulse pressure, Glu Glucose, $H D L$ - $C$ high-density lipoprotein cholesterol, $L D L$ - $C$ low-density lipoprotein cholesterol, Apo Apolipoprotein, TC Total cholesterol, TG Triglyceride. The value of triglyceride was presented as median (interquartile range), the difference between the control and CAD/Ischemic stroke groups was determined by the Wilcoxon-Mann-Whitney test

lower in ischemic stroke patients as compared with controls.

\section{Genotypic and allelic frequencies}

The genotypic scattering of the XKR6 rs7819412 SNP in both cases and controls conformed to Hardy-Weinberg equilibrium $(P>0.05)$. The genotypic as well as allelic frequencies of the rs7819412 SNP are represented in
Table 2. The frequencies of the $\mathrm{G}$ and $\mathrm{A}$ alleles were 92.5 and $7.5 \%$ in controls; 89.9 and $10.1 \%$ in CAD patients $(P=0.024$ vs. controls); and 90 and $10 \%$ in ischemic stroke patients ( $P=0.036$ vs. controls); respectively. The frequency of the GA/AA, GG genotypes were 14.3 and $85.7 \%$ in controls; 19 and $81 \%$ in CAD patients ( $P=0.025$ vs. controls); and 18.8 and $81.2 \%$ in ischemic stroke patients ( $P=0.029$ vs. controls); respectively.

Table 2 Genotype and allele frequencies of the XKR6 rs7819412 SNP in cases and controls [n (\%)]

\begin{tabular}{|c|c|c|c|c|c|c|c|}
\hline \multirow{2}{*}{$\begin{array}{l}\text { Genotype/ } \\
\text { Allele }\end{array}$} & \multirow{2}{*}{$\begin{array}{l}\text { Control } \\
(n=643)\end{array}$} & \multirow{2}{*}{$\begin{array}{l}\text { CAD } \\
(n=588)\end{array}$} & \multirow{2}{*}{$\begin{array}{l}\text { Ischemic } \\
\text { stroke } \\
(n=552)\end{array}$} & \multicolumn{2}{|l|}{ CAD } & \multicolumn{2}{|l|}{ Ischemic stroke } \\
\hline & & & & OR $(95 \% \mathrm{Cl})$ & $P$ & OR $(95 \% \mathrm{Cl})$ & $P$ \\
\hline GG & $551(85.7)$ & $476(81.0)$ & $447(81.2)$ & 1 & & 1 & \\
\hline GA/AA & $92(14.3)$ & $112(19.0)$ & 105 (18.8) & 1.409 (1.042-1.906) & 0.026 & $1.407(1.036-1.911)$ & 0.029 \\
\hline$x^{2}$ & 0.576 & 0.197 & 0.052 & & & & \\
\hline $\operatorname{HWE}(P)$ & 0.448 & 0.657 & 0.820 & & & & \\
\hline$x^{2}$ & & 4.991 & 4.794 & & & & \\
\hline$P$ & & 0.025 & 0.029 & & & & \\
\hline G & 1189 (92.5) & 1057 (89.9) & $994(90.0)$ & 1 & & 1 & \\
\hline A & $97(7.5)$ & $119(10.1)$ & $110(10.0)$ & $1.380(1.042-1.827)$ & 0.024 & 1.356 (1.019-1.805) & 0.036 \\
\hline$x^{2}$ & & 5.094 & 4.401 & & & & \\
\hline$P$ & & 0.024 & 0.036 & & & & \\
\hline
\end{tabular}




\section{XKR6 rs7819412 SNP and the risk of CAD and ischemic stroke}

The A allele was connected with high risk of CAD (adjusted $\mathrm{OR}=1.38,95 \% \mathrm{CI}=1.042-1.827$ ) and ischemic stroke (adjusted OR $=1.365$, 95\% CI $=1.019-1.805$; Table $2)$. The GA/AA genotypes were also related to an increased risk of CAD (adjusted $\mathrm{OR}=1.409,95 \% \mathrm{CI}=$ $1.042-1.906$ ) and ischemic stroke (adjusted $\mathrm{OR}=1.407$, 95\% CI = 1.036-1.911). Unconditional logistic regression analysis showed that the subjects with GA/GG genotypes had high risk of $\mathrm{CAD}$ in the following subgroups: males (adjusted $\mathrm{OR}=1.448,95 \% \mathrm{CI}=1.034-2.141$ ), $\mathrm{BMI} \geq 24$ $\mathrm{kg} / \mathrm{m}^{2}$ (adjusted OR $=2.174,95 \% \mathrm{CI}=1.227-3.756$ ), and smokers (adjusted $\mathrm{OR}=2.630,95 \% \mathrm{CI}=1.593-4.342$ ). The patients with GA/GG genotypes had high risk of ischemic stroke in the following subgroups: males (adjusted $\mathrm{OR}=1.483, \quad 95 \% \quad \mathrm{CI}=1.023-2.148), \quad \mathrm{BMI} \geq 24 \mathrm{~kg} / \mathrm{m}^{2}$ (adjusted $\mathrm{OR}=1.713,95 \% \mathrm{CI}=1.048-2.858$ ), and smokers (adjusted $\mathrm{OR}=1.925,95 \% \mathrm{CI}=1.137-3.257$; Table 3 ). Some significant interactions were also detected in smoking, $\mathrm{BMI} \geq 24 \mathrm{~kg} / \mathrm{m}^{2}$ and genotypes.

\section{Related risk factors for CAD and ischemic stroke}

Unconditional logistic regression analysis revealed that the incidence of CAD and ischemic stroke was positively correlated with hyperlipidemia, BMI, hypertension, smoking, diabetes, and the rs7819412 GA/AA genotypes and negatively correlated with alcohol consumption (Table 4).

\section{Genotypes and serum lipid levels}

The XKR6 rs7819412A allele carriers had higher serum TC levels in ischemic stroke and higher serum TG levels in CAD patients than the rs7819412A allele non-carriers $(P<0.05$; Table 5).

\section{Relative factors for serum lipid parameters}

As shown in Fig. 1, Pearson correlation analysis suggested that the rs7819412 SNP was connected with serum lipid levels, and several environmental factors such as sex, age, alcohol consumption, cigarette smoking, BMI and blood pressure levels were also correlated with serum lipid parameters in both patient groups.

\section{Discussion}

A previous study suggested that the incidence and progress of CAD were influenced by both environmental and genetic factors and their interactions [26]. Hundreds of GWASes indicated that lots of SNPs have been related to some risk factors that could contribute to the development of CAD, such as obesity, serum lipid levels

Table 3 The risk of rs7819412 for CAD and ischemic stroke according to body mass index (BMI), gender, smoking and drinking

\begin{tabular}{|c|c|c|c|c|c|c|c|}
\hline \multirow[t]{2}{*}{ Factors } & \multirow[t]{2}{*}{ Genetype } & \multicolumn{3}{|l|}{ CAD } & \multicolumn{3}{|l|}{ Ischemic stroke } \\
\hline & & OR (95\%Cl) & $P$ & $P$ interaction & OR $(95 \% \mathrm{Cl})$ & $P$ & P interaction \\
\hline \multicolumn{8}{|l|}{ BMI } \\
\hline \multirow[t]{2}{*}{$<24 \mathrm{Kg} / \mathrm{m}^{2}$} & GG & 1 & & 0.000 & 1 & & 0.006 \\
\hline & GA/AA & $1.229(0.841-1.795)$ & 0.287 & & 1.179 (0.793-1.753) & 0.416 & \\
\hline \multirow[t]{2}{*}{$\geq 24 \mathrm{Kg} / \mathrm{m}^{2}$} & GG & 1 & & & 1 & & \\
\hline & GA/AA & $2.174(1.227-3.756)$ & 0.007 & & $1.731(1.048-2.858)$ & 0.032 & \\
\hline \multicolumn{8}{|l|}{ Gender } \\
\hline \multirow[t]{2}{*}{ Male } & GG & 1 & & 0.058 & 1 & & 0.735 \\
\hline & GA/AA & $1.448(1.034-2.141)$ & 0.032 & & $1.483(1.023-2.148)$ & 0.037 & \\
\hline \multirow[t]{2}{*}{ Female } & GG & 1 & & & 1 & & \\
\hline & GA/AA & $1.250(0.725-2.153)$ & 0.422 & & $1.243(0.719-2.151)$ & 0.436 & \\
\hline \multicolumn{8}{|l|}{ Smoking } \\
\hline \multirow[t]{2}{*}{ Nonsmoker } & GG & 1 & & 0.000 & 1 & & 0.014 \\
\hline & GA/AA & $1.185(0.813-1.727)$ & 0.378 & & $1.205(0.823-1.765)$ & 0.338 & \\
\hline \multirow[t]{2}{*}{ Smoker } & GG & 1 & & & 1 & & \\
\hline & GA/AA & $2.630(1.593-4.342)$ & 0.000 & & $1.925(1.137-3.257)$ & 0.015 & \\
\hline \multicolumn{8}{|l|}{ Drinking } \\
\hline \multirow[t]{2}{*}{ Nondrinker } & GG & 1 & & 0.481 & 1 & & 0.126 \\
\hline & GA/AA & $1.238(0.859-1.784)$ & 0.253 & & $1.266(0.876-1.830)$ & 0.210 & \\
\hline \multirow[t]{2}{*}{ Drinker } & GG & 1 & & & 1 & & \\
\hline & GA/AA & $1.737(0.993-3.037)$ & 0.053 & & $1.514(0.943-2.672)$ & 0.152 & \\
\hline
\end{tabular}


Table 4 The relative risk factors for CAD and Ischemic stroke

\begin{tabular}{|c|c|c|c|c|}
\hline \multirow[t]{2}{*}{ Factor } & \multicolumn{2}{|l|}{ CAD } & \multicolumn{2}{|l|}{ Ischemic stroke } \\
\hline & OR $(95 \% \mathrm{Cl})$ & $P$ & OR $(95 \% \mathrm{Cl})$ & $P$ \\
\hline $\mathrm{BMI}<24 \mathrm{~kg} / \mathrm{m}^{2}$ & 1 & & 1 & \\
\hline $\mathrm{BMI} \geq 24 \mathrm{~kg} / \mathrm{m}^{2}$ & $1.417(1.118-1.795)$ & 0.004 & $1.542(1.204-1.975)$ & 0.001 \\
\hline Nonsmoking & 1 & & 1 & \\
\hline Smoking & $1.306(1.020-1.674)$ & 0.034 & $1.477(1.136-1.920)$ & 0.004 \\
\hline Nondrinking & 1 & & 1 & \\
\hline Drinking & $0.556(0.424-0.728)$ & 0.010 & $0.414(0.316-0.544)$ & 0.000 \\
\hline Rs7819412GG & 1 & & 1 & \\
\hline Rs7819412GA/AA & $1.533(1.131-2.077)$ & 0.006 & $1.461(1.067-2.001)$ & 0.018 \\
\hline Non-diabetes & 1 & & 1 & \\
\hline Diabetes & $1.476(1.080-2.018)$ & 0.015 & $1.486(1.117-1.977)$ & 0.006 \\
\hline Normotensive & 1 & & 1 & \\
\hline Hypertension & $1.192(0.889-1.600)$ & 0.240 & $1.250(0.974-1.604)$ & 0.079 \\
\hline Normal serum lipids & 1 & & 1 & \\
\hline Hyperlipidemia & 1.439 (1.133-1.828) & 0.003 & $1.582(1.219-2.053)$ & 0.001 \\
\hline
\end{tabular}

and hypertension [27-29]. Recent research suggested that a healthy lifestyle among individuals with high genetic risk profile could reduce the relative risk of CAD by nearly $50 \%$ compared with a poor lifestyle, suggesting that genotyping and early lifestyle intervention could effectively reduce the incidence of CAD in high-risk group [30]. The current study showed that the allelic and genotypic frequencies of the rs7819412 SNP were markedly different between controls and patients with ischemic stroke or CAD, and the A allele and GA/AA genotypes were associated with an increased risk of ischemic stroke and CAD in the Han Chinese. In other words, the rs7819412 SNP may be a genetic risk factor for ischemic stroke and CAD.

Previous work demonstrated that the rs7819412 SNP was linked to increased TG levels and T2DM in Europeans [16, 31]. A lot of studies showed that hyperlipidemia and T2DM were the severe risk factors for $\mathrm{CAD}$ and ischemic stroke, these risk factors are evenly related to the increased incidence of both diseases

Table 5 Association of the genotypes and serum lipid levels in controls and CAD and ischemic stroke patients

\begin{tabular}{|c|c|c|c|c|c|c|c|c|}
\hline Genotype & $n$ & $\begin{array}{l}\mathrm{TC} \\
(\mathrm{mmol} / \mathrm{L})\end{array}$ & $\begin{array}{l}\mathrm{TG} \\
(\mathrm{mmol} / \mathrm{L})\end{array}$ & $\begin{array}{l}\mathrm{HDL}-\mathrm{C} \\
(\mathrm{mmol} / \mathrm{L})\end{array}$ & $\begin{array}{l}\mathrm{LDL}-\mathrm{C} \\
(\mathrm{mmol} / \mathrm{L})\end{array}$ & $\begin{array}{l}\text { ApoA1 } \\
(\mathrm{g} / \mathrm{L})\end{array}$ & $\begin{array}{l}\text { ApoB } \\
\text { (g/L) }\end{array}$ & $\begin{array}{l}\text { ApoA1/ } \\
\text { ApoB }\end{array}$ \\
\hline \multicolumn{9}{|l|}{ Control } \\
\hline GG & 551 & $4.35 \pm 1.04$ & $1.35 \pm 1.70$ & $1.90 \pm 0.49$ & $2.74 \pm 0.76$ & $1.42 \pm 0.28$ & $0.91 \pm 0.21$ & $1.66 \pm 0.58$ \\
\hline GA/AA & 92 & $4.25 \pm 1.07$ & $1.54 \pm 2.11$ & $1.85 \pm 0.50$ & $2.61 \pm 0.87$ & $1.38 \pm 0.26$ & $0.88 \pm 0.21$ & $1.63 \pm 0.40$ \\
\hline$F$ & & 1.306 & 0.987 & 0.941 & 2.276 & 0.924 & 0.444 & 0.228 \\
\hline$P$ & & 0.254 & 0.321 & 0.332 & 0.132 & 0.337 & 0.505 & 0.633 \\
\hline \multicolumn{9}{|l|}{ CAD } \\
\hline GG & 476 & $4.55 \pm 1.19$ & $1.59 \pm 1.00$ & $1.15 \pm 0.34$ & $2.82 \pm 0.99$ & $1.02 \pm 0.32$ & $0.91 \pm 0.26$ & $1.23 \pm 0.84$ \\
\hline GA/AA & 112 & $4.57 \pm 1.33$ & $1.92 \pm 1.48$ & $1.15 \pm 0.34$ & $3.00 \pm 1.16$ & $1.06 \pm 0.45$ & $0.90 \pm 0.28$ & $1.27 \pm 0.58$ \\
\hline$F$ & & 0.004 & 7.267 & 0.100 & 2.719 & 1.411 & 0.491 & 0.344 \\
\hline P & & 0.952 & 0.007 & 0.752 & 0.100 & 0.235 & 0.484 & 0.558 \\
\hline \multicolumn{9}{|c|}{ Ischemic stroke } \\
\hline GG & 447 & $4.49 \pm 1.15$ & $1.64 \pm 1.24$ & $1.23 \pm 0.42$ & $2.81 \pm 0.87$ & $1.02 \pm 0.22$ & $0.89 \pm 0.24$ & $1.25 \pm 0.47$ \\
\hline GA/AA & 105 & $4.73 \pm 1.21$ & $1.85 \pm 2.17$ & $1.27 \pm 0.37$ & $2.92 \pm 1.07$ & $1.05 \pm 0.26$ & $0.93 \pm 0.27$ & $1.26 \pm 0.60$ \\
\hline$F$ & & 4.270 & 1.672 & 0.887 & 1.822 & 0.985 & 3.254 & 0.000 \\
\hline$P$ & & 0.039 & 0.197 & 0.347 & 0.178 & 0.321 & 0.072 & 0.993 \\
\hline
\end{tabular}

Adjusted for sex, age, smoking, drinking, BMI, diabetes, hypertension, hyperlipidemia. $T C$ total cholesterol, $T G$ triglyceride, $H D L-C$ high-density lipoprotein cholesterol, LDL-C low-density lipoprotein cholesterol, ApoA1 apolipoprotein A1, ApoB apolipoprotein B, CAD Coronary artery disease 


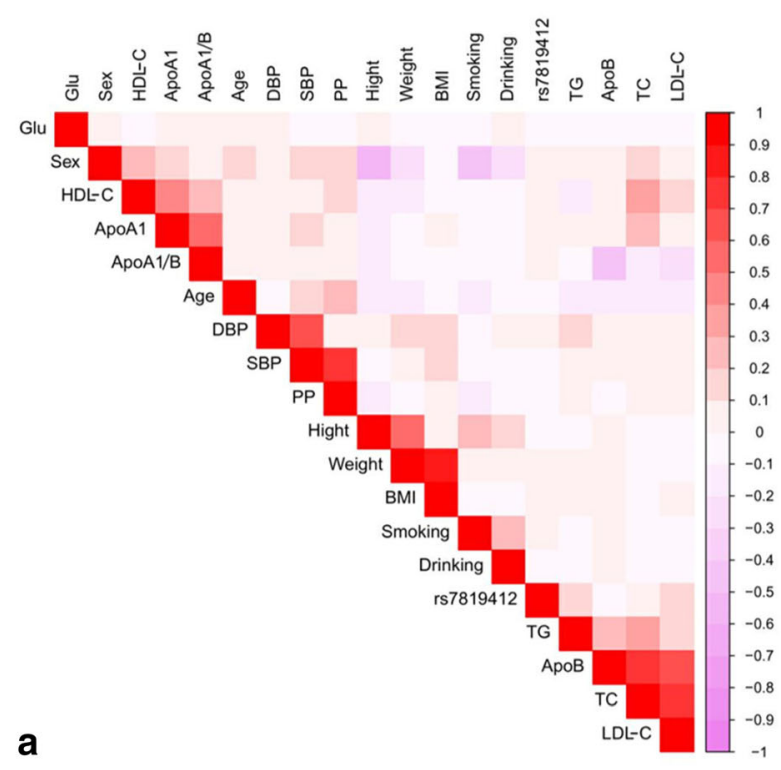

CAD,Genotype and Environmental Factors and Serum lipids

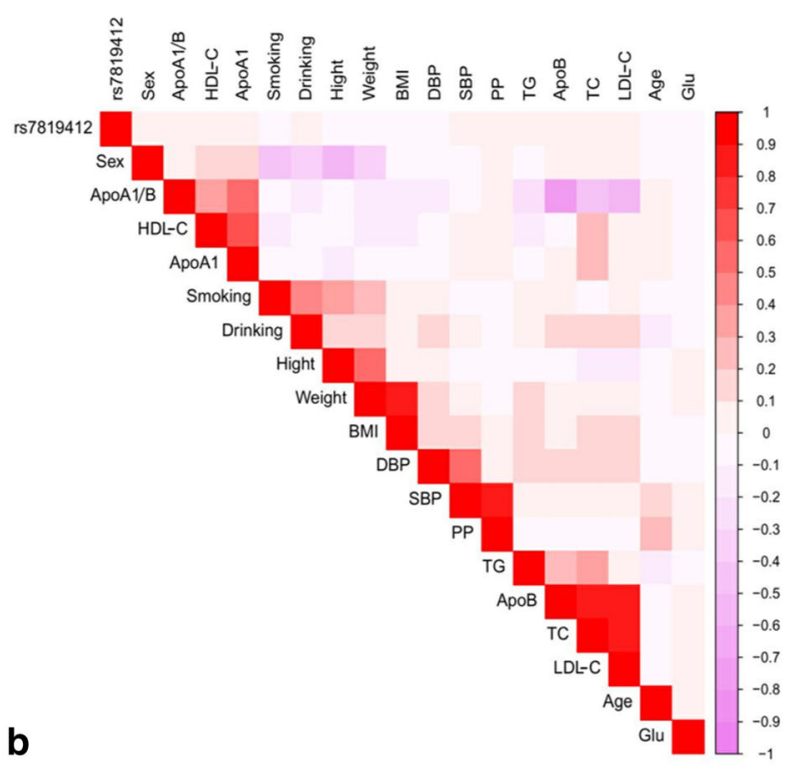

Ischemic stroke, Genotype and Environmental Factors and Serum lipids

Fig. 1 Correlation among environmental exposures, the XKR6 rs7819412 SNP and serum lipid variables in the patients with CAD (a) or ischemic stroke (b). CAD Coronary artery disease; TC total cholesterol; TG triglyceride; HDL-C high-density lipoprotein cholesterol; $L D L-C$ low-density lipoprotein cholesterol; $A p \circ A 1$ apolipoprotein A1; $A p o B$ apolipoprotein $B ; A p o A 1 / B$ the ratio of apolipoprotein A1 to apolipoprotein B; BMI body mass index

[32-35]. Thus, we speculated that the rs7819412 SNP might be related to the incidence of ischemic stroke and CAD. In the current research, we noticed that the patients with A allele had increased TG levels in CAD and TC levels in ischemic stroke patients, and we also found that the GA/AA genotypes and A allele were connected with high risk of $\mathrm{CAD}$ and ischemic stroke.

In the present study, we also found that the subjects with GA/AA genotypes had an increased risk of CAD in the following subgroups: males, high BMI and smokers. It is well-known that people with high BMI had higher mortality and incidence of cardiac events [36]. Several previous studies have proved that obesity is a shared and most important risk factor for several different types of cardiovascular and cerebrovascular diseases, such as heart failure, ischemic stroke and CAD [37-39]. Furthermore, it has been noticed that there are significant differences in height, weight, and mass and distribution of fat between males and females. It is essential to take these differences into consideration in assessing the meaning of cardiac symptoms between men and women, and these differences indicate that there may be a sexspecific in the occurrence and development of CAD [40]. Gender is considered as a self-determining risk element for dyslipidemia, cardiovascular disease and ischemic stroke. In addition, the influence of smoking on dyslipidemia has attracted more and more attention. Several recent studies noted that the lower HDL-C levels and increased ratio of the ApoA1/ApoB and serum TG, LDL-C, TC levels in smokers compared to non-smokers, all of these were related to the development of CAD and ischemic stroke [41-43]. In our research, the interaction between the XKR6 rs7819412 SNP and gender, high BMI and smoking was found and the risk of CAD and ischemic stroke was also increased.

It is now generally accepted that the cholesterollowering action of lipid-lowering drugs is the most important factor to reduce the occurrence of adverse events and mortality in patients with CAD and ischemic stroke [44]. But, genotyping of high-risk population could produce great significance for the early prevention of CAD and ischemic stroke, and it has also attracted more attentions. In our research, we proved that the XKR6 rs7819412 SNP not only contributed to serum lipid levels and increased the risk of CAD and ischemic stroke, but also interacted with several environment factors. Therefore, the XKR6 rs7819412 SNP may be a new target for early prevention and treatment of hyperlipidemia and atherosclerosis-related diseases.

\section{Limitations}

This study may have several limitations. Firstly, the number of cases was relatively small as compared to other studies. Thus, a study with larger sample size was needed to demonstrate our results. Secondly, many patients were taking some drugs that were used for secondary prevention of CAD. All drugs have some certain impacts on serum lipid levels. Thirdly, although several environmental factors such as sex, age, blood pressure, cigarette smoking, BMI and alcohol 
consumption have been adjusted for the statistical analysis, some general characteristics were different between controls and cases. Finally, in spite of we noticed that the rs7819412 A allele was connected with increased serum TG, TC levels and the risk of CAD and ischemic stroke, in order to further clarify the mechanism, some efficient studies should be carried out.

\section{Conclusions}

The results of the present study showed that the genotypic and allelic frequencies of the XKR6 rs7819412 SNP were obviously different between controls and patients with CAD and ischemic stroke. The GA/AA genotypes were associated with increased serum TG levels in CAD and TC levels in ischemic stroke patients. The patients with GA/AA genotypes or A allele had an increased risk of $\mathrm{CAD}$ and ischemic stroke in the following subgroups: males, BMI $\geq 24 \mathrm{~kg} / \mathrm{m}^{2}$ and smokers.

\section{Abbreviations}

ANCOVA: Covariance analysis; Apo: Apolipoprotein; BMl: Body mass index CAD: Coronary artery disease; Cl: Confidence interval; DNA: Deoxyribonucleic acid; GWAS: Genome-wide association study; HDL-C: High-density lipoprotein cholesterol; LDL-C: Low-density lipoprotein cholesterol; OR: Odds ratio; SNP: Single nucleotide polymorphisms; T2DM: Type 2 diabetes mellitus; TC: Total cholesterol; TG: Triglyceride; XKR6: XK related 6

\section{Acknowledgements}

We are grateful to all the participants of this study and the staff from the Guangxi Key Laboratory Base of Precision Medicine in Cardio-cerebrovascular Disease Control and Prevention.

\section{Authors' contributions}

P-FZ conceived the study, participated in the design, performed the statistical analyses, and drafted the manuscript. R-XY conceived the study, participated in the design, carried out the epidemiological survey, collected the samples, and helped to draft the manuscript. G-XD, Y-ZG, B-LW and C-XL carried out the epidemiological survey and collected the samples. All authors read and approved the final manuscript.

\section{Funding}

This study was supported by the National Natural Science Foundation of China (No. 81460169). There was no role of the funding body in the design of the study and collection, analysis, and interpretation of data and in writing the manuscript.

\section{Availability of data and materials}

The datasets generated during the present study are not publicly available, because detailed genetic information of each participant was included in these materials.

\section{Ethics approval and consent to participate}

The study design was approved by the Ethics Committee of the First Affiliated hospital, Guangxi Medical University (No: Lunshen-2011-KY-Guoji-001; Mar. 7, 2011). Written informed consent was obtained from all participants.

\section{Consent for publication}

Not applicable.

\section{Competing interests}

The authors declare that they have no competing interests.

\section{Author details}

'Department of Cardiology, Institute of Cardiovascular Diseases, the First Affiliated Hospital, Guangxi Medical University, Nanning 530021, Guangxi, People's Republic of China. ${ }^{2}$ Guangxi Key Laboratory Base of Precision Medicine in Cardio-cerebrovascular Disease Control and Prevention, Nanning
530021, Guangxi, People's Republic of China. ${ }^{3}$ Guangxi Clinical Research Center for Cardio-cerebrovascular Diseases, Nanning 530021, Guangxi, People's Republic of China.

Received: 26 April 2019 Accepted: 6 August 2019

Published online: 20 August 2019

\section{References}

1. Castelli WP. Cholesterol and lipids in the risk of coronary artery disease--the Framingham Heart Study. Can J Cardiol. 1988;4(Suppl A):5A-10A.

2. Yokokawa H, Yasumura S, Tanno K, Ohsawa M, Onoda T, Itai K, et al. Serum low-density lipoprotein to high-density lipoprotein ratio as a predictor of future acute myocardial infarction among men in a 2.7-year cohort study of a Japanese northern rural population. J Atheroscler Thromb. 2011;18(2):89-98.

3. Finegold JA, Asaria P, Francis DP. Mortality from ischaemic heart disease by country, region, and age: statistics from World Health Organisation and United Nations. Int J Cardiol. 2013;168(2):934-45.

4. Chow CK, Jolly S, Rao-Melacini P, Fox KA, Anand SS, Yusuf S. Association of diet, exercise, and smoking modification with risk of early cardiovascular events after acute coronary syndromes. Circulation. 2010;121(6):750-8.

5. Li Y, Tang K, Zhou K, Wei Z, Zeng Z, He L, et al. Quantitative assessment of the effect of ABCA1 R219K polymorphism on the risk of coronary heart disease. Mol Biol Rep. 2012;39(2):1809-13.

6. Libby P, Theroux P. Pathophysiology of coronary artery disease. Circulation. 2005;111(25):3481-8.

7. Holmstedt CA, Turan TN, Chimowitz MI. Atherosclerotic intracranial arterial stenosis: risk factors, diagnosis, and treatment. Lancet Neurol. 2013;12(11): 1106-14.

8. Crouse JR, Parks JS, Schey HM, Kahl FR. Studies of low density lipoprotein molecular weight in human beings with coronary artery disease. J Lipid Res. 1985;26(5):566-74.

9. Kwiterovich PO Jr, Coresh J, Smith HH, Bachorik PS, Derby CA, Pearson TA. Comparison of the plasma levels of apolipoproteins $B$ and $A-1$, and other risk factors in men and women with premature coronary artery disease. Am J Cardiol. 1992;69(12):1015-21.

10. Criqui MH, Heiss G, Cohn R, Cowan LD, Suchindran CM, Bangdiwala S, et al. Plasma triglyceride level and mortality from coronary heart disease. N Engl J Med. 1993;328(17):1220-5.

11. Shekelle RB, Shryock AM, Paul O, Lepper M, Stamler J, Liu S, et al. Diet, serum cholesterol, and death from coronary heart disease. The Western electric study. N Engl J Med. 1981;304(2):65-70.

12. Silbernagel G, Schottker B, Appelbaum S, Scharnagl H, Kleber ME, Grammer $T B$, et al. High-density lipoprotein cholesterol, coronary artery disease, and cardiovascular mortality. Eur Heart J. 2013:34(46):3563-71.

13. Heller DA, De Faire U, Pedersen NL, Dahlén G, Mcclearn GE. Genetic and environmental influences on serum lipid levels in twins. N Engl J Med. 1993; 328(16):1150-6.

14. Marenberg ME, Risch N .., Berkman LF, Floderus B, .. De Faire U. Genetic susceptibility to death from coronary heart disease in a study of twins. N Engl J Med 1994;330(15):1041-1046.

15. Willer CJ, Schmidt EM, Sengupta S, Peloso GM, Gustafsson S, Kanoni S, et al. Discovery and refinement of loci associated with lipid levels. Nat Genet. 2013;45(11):1274-83

16. De Silva NM, Freathy RM, Palmer TM, Donnelly LA, Luan J, Gaunt T, et al. Mendelian randomization studies do not support a role for raised circulating triglyceride levels influencing type 2 diabetes, glucose levels, or insulin resistance. Diabetes. 2011;60(3):1008-18.

17. Franceschini N, Carty C, Buzkova P, Reiner AP, Garrett T, Lin Y, et al. Association of genetic variants and incident coronary heart disease in multiethnic cohorts: the PAGE study. Circ Cardiovasc Genet. 2011;4(6):661-72.

18. Touati A, Blouin $Y$, Sirand-Pugnet $P$, Renaudin $H$, Oishi T, Vergnaud $G$, et al. Molecular epidemiology of mycoplasma pneumoniae: genotyping using single nucleotide polymorphisms and SNaPshot technology. J Clin Microbiol. 2015;53(10):3182-94.

19. Miao L, Yin RX, Yang S, Huang F, Chen WX, Cao XL. Association between single nucleotide polymorphism rs9534275 and the risk of coronary artery disease and ischemic stroke. Lipids Health Dis. 2017;16(1):193.

20. Guo T, Yin RX, Nie RJ, Chen X, Bin Y, Lin WX. Suppressor of cytokine signaling 3 a+930-->G (rs4969168) polymorphism is associated with apolipoprotein A1 and low-density lipoprotein cholesterol. Int J Clin Exp Pathol. 2015;8(6):7305-17. 
21. Zeng XN, Yin RX, Huang P, Huang KK, Wu J, Guo T, et al. Association of the MLXIPL/TBL2 rs17145738 SNP and serum lipid levels in the Guangxi Mulao and Han populations. Lipids Health Dis. 2013;12:156.

22. Ramazauskiene $\mathrm{V}$. Diet and serum lipids: changes over socio-economic transition period in Lithuanian rural population. BMC Public Health. 2011;11(1):447.

23. Whitworth JA. 2003 World Health Organization (WHO)/International Society of Hypertension (ISH) statement on management of hypertension. J Hypertens. 2003;21(11):1983-92.

24. Zhou BF. Predictive values of body mass index and waist circumference for risk factors of certain related diseases in Chinese adults--study on optimal cut-off points of body mass index and waist circumference in Chinese adults. Biomed Environ Sci. 2002;15(1):83-96.

25. Alberti G, Zimmet PZ. Definition, diagnosis and classification of diabetes mellitus and its complications. Part 1: diagnosis and classification of diabetes mellitus. Provisional report of a WHO Consultation. Diabet Med. 1998;15(7):539-53.

26. Shukla H, Mason JL, Sabyah A. Identifying genetic markers associated with susceptibility to cardiovascular diseases. Future Sci OA. 2019;5(1):Fso350.

27. Wellcome Trust Case Control Consortium. Genome-wide association study of 14,000 cases of seven common diseases and 3,000 shared controls. Nature. 2007:447(7145):661-78.

28. Kathiresan S, Willer CJ, Peloso GM, Demissie S, Musunuru K, Schadt EE, et al. Common variants at 30 loci contribute to polygenic dyslipidemia. Nat Genet. 2009;41(1):56-65.

29. Deloukas P, Kanoni S, Willenborg C, Farrall M, Assimes TL, Thompson JR, et al. Large-scale association analysis identifies new risk loci for coronary artery disease. Nat Genet. 2013;45(1):25-33.

30. Khera AV, Emdin CA, Drake I, Natarajan P, Bick AG, Cook NR, et al. Genetic risk, adherence to a healthy lifestyle, and coronary disease. N Engl J Med. 2016:375(24):2349-58.

31. Jeemon P, Pettigrew K, Sainsbury C, Prabhakaran D, Padmanabhan S. Implications of discoveries from genome-wide association studies in current cardiovascular practice. World J Cardiol. 2011;3(7):230-47.

32. Gao W, He HW, Wang ZM, Zhao H, Lian XQ, Wang YS, et al. Plasma levels of lipometabolism-related miR-122 and miR-370 are increased in patients with hyperlipidemia and associated with coronary artery disease. Lipids Health Dis. 2012;11:55.

33. Infante T, Forte $\mathrm{E}$, Aiello M, Salvatore M, Cavaliere C. In vivo and in vitro analysis in coronary artery disease related to type 2 diabetes. Front Endocrinol (Lausanne). 2017:8:209.

34. Larsson SC, Scott RA, Traylor M, Langenberg CC, Hindy G, Melander O, et al. Type 2 diabetes, glucose, insulin, BMI, and ischemic stroke subtypes: Mendelian randomization study. Neurology. 2017;89(5):454-60.

35. Yeramaneni S, Kleindorfer DO, Sucharew H, Alwell K, Moomaw CJ, Flaherty $\mathrm{ML}$, et al. Hyperlipidemia is associated with lower risk of poststroke mortality independent of statin use: a population-based study. Int J Stroke. 2017:12(2):152-60

36. Bangalore S, Fayyad R, Laskey R, Demicco DA, Messerli FH, Waters DD. Bodyweight fluctuations and outcomes in coronary disease. N Engl J Med. 2017; 376(14):1332-40

37. Aune D, Sen A, Norat T, Janszky I, Romundstad P, Tonstad S, et al. Body mass index, abdominal fatness, and heart failure incidence and mortality: a systematic review and dose-response meta-analysis of prospective studies. Circulation. 2016;133(7):639-49.

38. Pandey A, Berry JD, Lavie CJ. Cardiometabolic disease leading to heart failure: better fat and fit than lean and lazy. Curr Heart Fail Rep. 2015;12(5):302-8.

39. Zalesin K, Franklin B, Miller WM, Peterson E, Mccullough P. Impact of obesity on cardiovascular disease. Med Clin North Am. 2008;95(5):919-37.

40. Legato MJ. Gender and the heart: sex-specific differences in normal anatomy and physiology. J Gend Specif Med. 2000;3(7):15-8.

41. Maeda K, Noguchi Y, Fukui T. The effects of cessation from cigarette smoking on the lipid and lipoprotein profiles: a meta-analysis. Prev Med. 2003;37(4):283-90.

42. Xu T, Holzapfel C, Dong X, Bader E, Yu Z, Prehn C, et al. Effects of smoking and smoking cessation on human serum metabolite profile: results from the KORA cohort study. BMC Med. 2013:11(1):60.

43. Kohei T, Satoshi I, Emi K, Yasunori S, Tomohiko S, Satomi A, et al. Impact of cigarette smoking cessation on high-density lipoprotein functionality. Circ J. 2014;78(12):2955-62

44. Wenger NK, Shaw $\sqcup$, Vaccarino V. Coronary heart disease in women: update 2008. Clin Pharmacol Ther. 2008;83(1):37-51.

\section{Publisher's Note}

Springer Nature remains neutral with regard to jurisdictional claims in published maps and institutional affiliations.
Ready to submit your research? Choose BMC and benefit from:

- fast, convenient online submission

- thorough peer review by experienced researchers in your field

- rapid publication on acceptance

- support for research data, including large and complex data types

- gold Open Access which fosters wider collaboration and increased citations

- maximum visibility for your research: over $100 \mathrm{M}$ website views per year

At BMC, research is always in progress.

Learn more biomedcentral.com/submissions 